\title{
AC 2011-2122: DEVELOPMENT OF NOVEL LEARNING MATERIALS FOR GREEN ENERGY EDUCATION CENTERED AROUND A PHOTO- VOLTAIC (PV) TEST STATION
}

\section{Hirak C Patangia, University of Arkansas, Little Rock}

Dr. Hirak Patangia is a Professor of Electronics and Computer in the College of Engineering and Information Technology at the University of Arkansas-Little Rock.He has served the University in various administrative positions including interim dean, associate dean, and department chair before returning to full-time teaching and research.He is a strong proponent of undergraduate research and many of his publications include undergraduates as coauthors.. With NSF funding, he developed a project based freshman engineering course for engineering and other university students who want to explore engineering as a career path or for personal enrichment. He has written a textbook and a laboratory manual for the course 'Introduction to Electronics and Electrical Systems: A PBL Approach'.He has received numerous awards for teaching excellence at UALR including Donaghey Outstanding Teacher award. He has also received recognition for research excellence from the chancellor and college. His research interest is in the general area of signal processing (analog/digital) and he is working on new approaches in inverter design and solar controller to improve efficiency of solar energy conversion. He received the bachelor's degree with honors from Indian Institute of Technology, Kharagpur and Ph.D. degree from McGill University, Canada, all degrees in Electrical Engineering. 


\title{
DEVELOPMENT OF NOVEL LEARNING MATERIALS FOR GREEN ENERGY EDUCATION CENTERED AROUND A PHOTOVOLTAIC (PV) TEST STATION
}

\begin{abstract}
$\underline{\text { Abstract }}$
A CCLI Type I NSF proposal under the heading of the paper title was awarded in August, 2010 to develop exemplarary learning materials and laboratory modules for PV (Photovoltaic) engineering at the undergraduate/graduate level. It's too early to present any real project outcome at this time, although active preparations are underway. The paper discusses the planned activities and implementation strategies of the proposed work.
\end{abstract}

\section{$\underline{\text { Introduction }}$}

With energy cost rising and the dangers of climate change due to energy-related greenhouse effect, there has been a great national interest in renewable energy. Energy security has been a public concern. Among the clean and green power sources, the photovoltaic solar power has the potential to supply a significant fraction of electrical energy need. With the sky rocketing gas price of past years, people are paying serious attention to alternate energy and this enthusiasm must be carried on to undergraduate engineering education. As a cornerstone of his energy, environment, and economic plans, President Barack Obama urges the country to transform its energy system to make it greener and smarter. This project seeks to address such a challenge with contemporary courses on alternate energy harnessing and electric smart grid (ESG).

A web search shows that many universities across the nation have been engaged in solar energy research. One of the goals is to improve physical properties of silicon cells to improve panel efficiency. Application of nanotechnology to improve the conversion efficiency of incoming light photons to electrical output has been a topic of high interest. Optical concentrators have been researched to improve panel efficiency. However, undergraduate courses that focus on the practical design and implementation of solar system starting with the panel to end user are virtually absent in the literature. Many courses across the nation are ME courses that focus more on solar radiation and the thermal aspect. A few EE courses devote about fifty percent of the course to semiconductors and the remaining to system hardware. The fundamentals of the system components are covered in other courses in EE curriculum and no focus on integration to solar conversion is presented. However this approach needs serious revision in view of the importance and national focus on harnessing alternate energy, and the need for graduates trained in this field. In the design of the proposed course materials, emphasis will be placed on the hardware design starting from the solar panel output to end user and grid connectivity. Physics of panel semiconductor will be left to other courses. Integration of our research finding from previous and current work $[1,2]$ will be a major factor in the course design.

\section{$\underline{\text { Project Objectives }}$}

The project focuses on four objectives: 


\section{Objective 1:}

Expand capacity of existing solar panels and establish a $2.5 \mathrm{KW}$ PV test station with associated instrumentation. This will be completed within the first year of the project.

\section{Objective 2:}

Develop contemporary course materials and hardware laboratory exercises for an upper level engineering course. Work will begin immediately and is to be completed by the end of summer of year 2. The PI (Principal Investigator) will develop the lecture notes while the RA (Research Assistant) and the undergraduates will support him with simulation exercises, testing of the laboratory experiments, and designing of presentation slides. First offering of the course is planned in the fall semester of second year.

\section{Objective 3:}

Develop few lab modules by the project senior personnel to be incorporated into a course on electric power grids. The lab module will train students to design, implement, and test a prototype of the solar power generation toolkit. The task will be completed in the spring of third year.

\section{Objective 4:}

Plan and develop the outline of a lower level course on renewable energy which will be open to all students. The purpose of the course is to introduce all students to this upcoming field and sustainability design. This work will begin in the spring of third year to develop the shell of the course with input from industry and a faculty committee.

\section{Project Implementation Plan}

The course materials will be developed to study each hardware component of the PV system shown in Fig. 1.

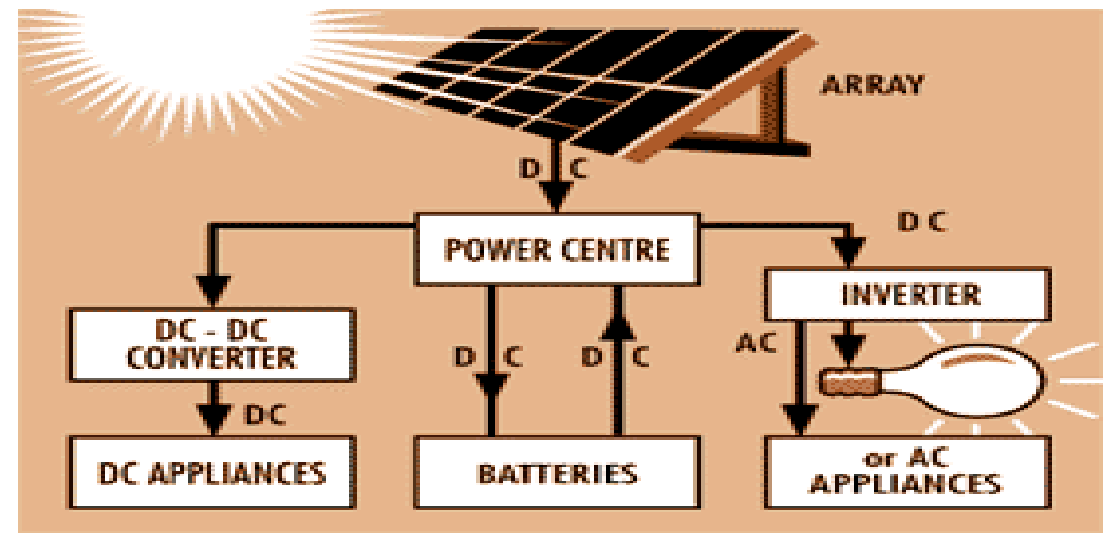

Fig. 1 A typical Solar System 
In a typical solar system, the solar array feeds a power management center which drives the load and charges the batteries at the same time. For night operation, the batteries provide the energy to the load. The major electrical components are DC-DC converter, DC-AC inverter, a power control system and the batteries. The figure shows a stand-alone system. A synopsis of the stateof-the-art concepts that would be included in the course development is included in the component description to provide a sample of the proposed materials.

\section{$\underline{D C-D C \text { Converter }}$}

There are various classical methods for DC-DC converters [3] which are typically included in the Analog Electronics or Power Electronics courses. New methods that avoid the use of inductors have been investigated in the literature $[4,5]$. Similar method was applied in a project for the highway department and the concept of amplitude-division-multiplexing was introduced as a framework to analyze this and other types of converters [6]. Time-Division Multiplexing (TDM) and Frequency Division Multiplexing (FDM) are well known concepts in communication systems [7]. The basic parameters that describe a signal are time, frequency, and amplitude. Therefore, it is natural to consider a multiplexing scheme that involves amplitude. Hitherto, there has been no mention of ADM as a multiplexing scheme in the literature, although such a multiplexing is done implicitly in various applications. However, for high voltage application, it is more insightful to consider this operation as an amplitude-division multiplexing function (lift and stack) from the view point of practical realization [8].

\section{$\underline{D C-A C \text { Inverter }}$}

Inverter is an essential component of photovoltaic system since array power generation is dc and electrical devices are ac driven. The fundamentals of inverters are generally included in a power electronics course. Inverter efficiency is a critical issue in PV application due to solar panel's poor efficiency. An efficient electrical system will optimize panel requirements and thus reduce system cost. This module will incorporate modern techniques of inverter design and how to improve its efficiency. Its development will borrow PI's research experience from previous projects $[9,10]$. Using ADM approach, the research has resulted in more than 98\% efficiency in medium power inverters at full load [11].

\section{$\underline{\text { Power Center }}$}

This is a critical component in a PV system that manages power flow to battery and the load. It regulates the charging voltage not to exceed battery rating and also not to drain battery voltage below the minimum. Embedded controllers are generally used for this purpose that employs PWM techniques. For stand-alone system in lighting application, this unit also controls the light 'on'/'off' timing, brightness adjustment for inclement weather, and may put batteries in series or parallel connection depending on the inverter design. Maximum Peak Power Tracking (MPPT) and its power management is part of this block. Modern MPPT controller techniques and their algorithms will be included and low cost methods will focus on analog design [12]. 


\section{Grid Connectivity}

Recently, the American Recovery and Reinvestment Act (ARRA) was passed by the Congress and signed into law by President Obama on Feb. 17, 2009. In the ARRA, sufficient attention is given to activities of building a new electricity smart grid (ESG). As a nationwide initiative, ESG covers several fundamental issues. In particular, ESG will accommodate all generation and storage options and optimize its assets and operate more efficiently. An increasing demand for trained ESG graduates is expected. ESG will enable several renewable energy sources to be fully utilized. One of the representative types of such energy sources is the solar power. However, ESG must guarantee the power reliability for the $21^{\text {st }}$ century consumers. It has been recognized as a challenging task to integrate the isolated solar power sites into modern power grids. This is mainly because the solar power generation is dependent on weather conditions and time of day. In the future utility market involving ESG, the managers in a power supply company have to place their energy bids in a day-ahead market, announcing the hour of energy production, the energy amount, and the price. These kinds of activities are necessary to achieve the consumerlevel power quality. This mission is impossible without an effective optimization toolkit to manage the generation of solar power.

A new course on electric power grid with a strong focus on ESG will be offered as a special topic in fall, 2011. Few lab modules will be developed centered on the proposed PV system. The lab modules will train students to design, implement, and test a prototype of the solar power generation toolkit. The students will have opportunities to learn the essentials of statistics of the solar power generation, the basic picture of future utility market involving ESG, and compare the economics of the grid-connected and stand-alone solar photovoltaic systems.

\section{Project Outcomes}

The outcome objectives of the project are:

- Complete a 2-3 KW photovoltaic test station for undergraduate teaching/research and develop related learning materials.

- Alongside the PV station, develop laboratory facilities with direct access to solar panels to provide experiential knowledge of high voltage and high current power electronics employed in solar energy conversion.

- Provide simulation experience to students to investigate various topological methods to improve efficiency and THD in inverters.

- Develop expertise in dc to dc conversion for maximum power point controller design.

- Develop programming skills in embedded controller for power management and inverter control.

- Provide experiential know-how of modern battery technology for hybrid operation.

- Incorporate the facility's grid connectivity to a course on ESG.

\section{Conclusions}

An education specialist will develop assessment tools to evaluate the following questions during the progress and the end of the project. 
- What impact the project has on students in acquiring new knowledge and skills in alternate energy?

- Does course delivery and experiential learning support constructivist learning theory that asserts that knowledge is not simply transmitted from teacher to student, but is actively constructed by the mind of the learner through experiences?

- How effective is the experimental test bed in achieving a comprehensive knowledge of harnessing alternate energy?

- How effective are the learning modules in meeting the objective of green energy education?

- How does the new facility enhance the motivation and interest of students, and others in alternate energy?

- What is the impact of the project in motivating seniors into graduate studies in renewable energy or a career in energy field?

Evaluation of these questions will require several cycles of course offering. Formative assessment will assess the usefulness and relevance of the course modules in specific contexts to laboratory experience and engineering needs. The evaluator will use surveys and Web-CT to get student feedback to align the modules with their concerns, needs, and effectiveness of the resources, and input from the industrial power group/IEEE chapter for content direction. Summative assessment will involve an overall assessment both in terms of learning effectiveness and usefulness of proposed facility. The PI will present the course development in an IEEE chapter meeting to receive their assessment of the course modules. They are all practicing engineers in power and energy field (generally PE) and they will provide unbiased assessment of the materials. The education specialist will administer and analyze their written comments. This will allow the project team to improve on the teaching materials. The number of students opting for graduate studies or career in alternate energy will be a direct indicator for level of project success.

During the developmental phase, graduates and undergraduates who will be part of the project team will provide input from 'student perspective' as formative assessment for the experimental test bed. This will be a helpful guide in developing effective and 'student friendly' learning tools for the students. Materials will also be evaluated through peer-review as papers are submitted and presented in educational and technical conferences and journals.

Once the course materials are presented, it will be determined if the course tends to be more a 'graduate' course for undergraduates. If necessary, adjustments will be made and some advanced topics will be shifted to graduate courses later.

\section{Bibliography}

[1] H. Patangia, Final Report: Assisted Night Vision for Motorists in Highway Construction Zones (MBTC2064). www.mackblackwell.org/web/research/ 2064-patangia\%5CMBTC-2064.htm

[2] H. Patangia, Final Report: Solar Powered Lighting for Overhead Highway Signs - MBTC 2096, January 2009. www.mackblackwell.org 
[3] N. Mohan, T. M. Undeland, and W. P. Robbins, Power Electronics. $3^{\text {rd }}$ ed. Wiley-VCH, 2003.

[4] Henry Shu-hung Chung, "Design and Analysis of a Switched-Capacitor-Based Step-Up DC/DC Converter with Continuous Input Current”, IEEE Trans. Circuits and Systems-I: Fund. Theory and Applicat., vol. 46, no. 6, June 1999.

[5] K. K. Law, K. W. E. Cheng, and Y. P. Benny Yeung, "Design and Analysis of Switched-Capacitor-Based Step-Up Resonant Converters”, IEEE Trans. Circuits and Systems-I: Regular Papers, vol. 52, no. 5, May 2005

[6] H. Patangia, “Amplitude Division Multiplexing Scheme in Analog Signal Processing”, in Proc. IEEE Int. Midwest Symp. Circuits \& Systems, August 2005, Cincinnati, Ohio.

[7] B. P. Lathi, Modern Digital and Analog Communications Systems, (The Oxford Series in Electrical and Computer Engineering), $3^{\text {rd }}$ edition, Oxford University Press, April 1998.

[8] H.C. Patangia and D. Gregory, "High Voltage Signal Processing Using a Small Signal Approach” in Proc. IEEE 2007 ISSPIT, December 2007, Cairo, Egypt.

[9] H. Patangia and D. Gregory, "Sectionalized PWM(S-PWM): A New Multilevel Modulation Strategy,” in Proc. IEEE Int. Symp. Circuits \& Systems, May 2008, Seattle, WA.

[10] H. Patangia and D. Gregory, "A Class of Optimal Multilevel Inverters Based on Sectionalized PWM (SPWM) Modulation Strategy” IEEE MWSCAS 2009, August, 2009, Cancun, Mexico.

[11] H. Patangia and Dennis Gregory, “A Stand Alone PV System for Highway Lighting Application”. Proc. IEEE PVSC34, June 2009, Philadelphia.

[12] Hirak Patangia, Srinikhil Gupta Gourisetti, Afzal Siddiqui, and Sachin Sharma,”A Simplified PV Model for Low Power MPPT Controller Design”, in Proc. IEEE Asia Pacific Conf. Circuits \& Systems (APCCAS), December 2010, Kuala Lumpur.

\section{Acknowledgements}

The paper is based upon the project funded by the National Science Foundation under Grant No. DUE-0942327. 